\title{
Liddle's Syndrome Case Report-Unusual Presentation with Hypertension in Children
}

\author{
Haia Nasser $^{1 *}$, Susan Nasser ${ }^{1}$, Abo Zaid Said ${ }^{1}$, Zohar Meiri ${ }^{2}$, Ehsan $\mathbf{N}^{1}$, Mariam Daher ${ }^{1}$, Sami shhadi $^{1}$, \\ Boshra Nasser ${ }^{4}$, Wael Nasser ${ }^{3}$ \\ ${ }^{1}$ Department of Pediatrics, Baruch Padeh Poriya Medical Center, Lower Galilee, Israel \\ ${ }^{2}$ Department of Radiology, Baruch Padeh Poriya Medical Center, Lower Galilee, Israel \\ ${ }^{3}$ Nephrology \& Hypertension Division,Baruch-Padeh Poriya Medical Center, Lower Galilee, Israel \\ ${ }^{4}$ Faculty of Medicine in Galillee, Bar Ilan University, Israel \\ "Corresponding Author: Dr. Haia Nasser, Department of Pediatrics, Baruch Padeh Poriya Medical Center, Lower \\ Galilee, Israel, E-mail: haia_nasser@hotmail.com
}

Received: 30 October 2018; Accepted: 06 November 2018; Published: 19 November 2018

\begin{abstract}
Increased blood pressure in children is usually secondary to a known cause. It is very important to discover the cause of high blood pressure, to treat it before the development of complications, and to prevent morbidity and mortality at this age. In this article, we will present a case of a 10-years-old girl with increased blood pressure and hypokalemia, we have been excluded any other causes for the high blood pressure, and after a favorable response to appropriate treatment, Amiloride, with a supportive laboratory, she was diagnosed with Liddle Syndrome.
\end{abstract}

Keywords: Ovarian Tumors; Abdominal pain; Computed tomography; Pediatric tumors

\section{Introduction}

The incidence of high blood pressure in children is not common it is close to $1-5 \%$, most cases are secondary, and the most common cause of secondary high blood pressure in children is a kidney problem. In some cases, once the common causes of blood pressure have been ruled out, hypertension will be associated with an unknown cause. In these cases, there is a chance of a dominant or recessive hereditary disease that it is the cause of high blood pressure. In light of this, it is necessary to take into account the obvious hereditary causes in children. 
One of the causes of secondary pediatric hypertension is Liddle syndrome. This syndrome is a dominant hereditary disease, manifested in mutations in the sodium channels in the kidneys, which causes over-activation of the sodium channels independently of the aldosterone [1]. However, sporadic cases of Liddle's syndrome have been stated in the literature [2].

The final diagnosis of this disease is by genetic examination of a mutant in ENAC [2], but in our case and in many cases described in the diagnostic books, the diagnosis was based on the exclusion of other causes in addition to a good response to appropriate treatment. Blood pressure control and hypokalemia repair are achieved by treatment of sodium channel blockage by drugs such as allured or triamterene, but this treatment generally does not affect the level of aldosterone in the blood. Liddle syndrome also is known as Pseudoaldosteronism which is characterized by hyperaldosteronism (hypokalemia, high blood pressure, and metabolic alkalosis), but there is no increase in the level of aldosterone in the blood.

There are cases in which this syndrome is not diagnosed and not treated accordingly, causing multiple complications such as stroke, heart, and kidney problems and even death [3], so it is important to diagnose this disease and treat accordingly to avoid long-term complications.

\section{Case to Study}

A 10 years old girl had been admitted with complaints about Polydipsia and Polyuria that started before 1 month. In addition in the last two days, the vomiting has worsened, she had abdominal distension, and she was apathetic. In her history Oligohydramnios, she was born in the time with low birth weight $2 \mathrm{~kg}$, delayed motor development, without a family history of increased blood pressure in childhood. In her examination, the child was apathy, with a dysmorphic face, and increased blood pressure in all four limbs around 150/90, the rest of the physical examination with no significant findings. Her height and weight were in the third percentile.

A laboratory was sent including electrolytes and complete blood count, ECG was performed to rule out a cardiac problem, and thyroid function was performed. Electrolytes showed hypokalemia and metabolic alkalosis, and bilateral nephrocalcinosis was diagnosed by renal ultrasound. At first, treatment with potassium was started and the girl was treated as she had Barter syndrome but no improvement in blood pressure was seen. Later on, the level of renin was low, so in the differential diagnosis was Liddle syndrome and adrenal hyperplasia, so a total investigation was taken of hydroxyprogesterone and aldosterone (Table 1-4). The Liddle syndrome was suspected when we received low levels of renin, a normal level of 17-OHP, and aldosterone. In light of this, Amiloride treatment was started, and there was an improvement in blood pressure and the level of potassium in the blood.

\begin{tabular}{|l|l|l|}
\hline Lab & Serum Electrolytes & Urinary Electrolytes \\
\hline BUN mg/dl & 15 & - \\
\hline Creatinine mg/dl & 0.6 & 10 \\
\hline
\end{tabular}




\begin{tabular}{|c|c|c|}
\hline $\mathrm{Mg} \mathrm{mmol} / \mathrm{L}$ & 2.4 & \\
\hline Na mmol/L & 135 & 25 \\
\hline $\mathrm{K} \mathrm{mmol} / \mathrm{L}$ & 2.2 & 16 \\
\hline Chloride $\mathrm{mmol} / \mathrm{l}$ & 96 & 55 \\
\hline Bicarbonat $\mathrm{mmol} / \mathrm{lit}$ & 29 & - \\
\hline Osmolarity & 285 & 130 \\
\hline
\end{tabular}

Table 1: Laboratory Investigations.

\begin{tabular}{|l|l|}
\hline Renin & $0.06<($ normal ;3-40nng/DL \\
\hline 17-OHP & $0.5(0.03---0.9) n n g / D L$ \\
\hline Aldosterone & $6(1-15) \mathrm{PG} / \mathrm{DL}$ \\
\hline
\end{tabular}

Table 2: Laboratory Investigations.

\begin{tabular}{|l|l|l|l|l|l|l|}
\hline Blood pressure trend & Day 1 & Day 2 & Day 3 & Day 4 & Day 5 & Follow-up \\
\hline Systolic/Diastolic mmHg & $145 / 89$ & $140 / 80$ & $135 / 70$ & $131 / 69$ & $122 / 65$ & $112 / 60$ \\
\hline
\end{tabular}

Table 3: Blood pressure Trend.

\begin{tabular}{|l|l|l|l|l|l|l|}
\hline Potassium level trend & Day 1 & Day 2 & Day 3 & Day 4 & Day 5 & Follow-up \\
\hline & 2.2 & 2.2 & 2.4 & 2.95 & 3 & 3.4 \\
\hline
\end{tabular}

Table 4: Potassium Level trend.

\section{Discussion}

Liddle's syndrome is a rare autosomal dominant condition characterized by an ENAC mutation. Genetic studies have revealed that mutations affecting the cytosolic tail of the $i$ subunit of the epithelial sodium channel (ENaC) could lead to this disorder [4]. leading to a primary increase in sodium reabsorption from the collecting tubule and secretion of potassium in the majority of the cases. Patients mostly are young, although there are cases that are detected in adulthood. Liddle is a familial syndrome of severe hypertension, hypokalemia (in most cases) and metabolic alkalosis mimicking hyperaldosteronism [4]. However, these patients have low renin and aldosterone levels, and there is conservation of sodium and excretion of potassium in the absence of mineralocorticoid excess the treatment of Liddle's syndrome differs from other forms of essential or secondary hypertension [1], treatment with drugs that work on aldosterones such as Spironolactone and Eplerenone is ineffective [5]. But the treatments that block sodium channels in the kidneys such as Amiloride and Triamterene is also associated with control of blood pressure and potassium in the blood, and are considered to be effective in this syndrome [6, 7].

The symptoms of this syndrome are IUGR, delayed growth and lack of urine concentration in the kidneys that it is secondary to chronic hypokalemia [8], and in rare cases secondary to hypercalciuria and nephrocalcinosis, which is 
unclear. It is important to note the importance of genetic counseling and to detect other children in the same family because it is a hereditary disease. It is necessary to monitor renal function, heart, and growth, usually, appropriate treatment and follow-up reduce the long-term complications.

\section{References}

1. Sagnella GA, Swift PA. The renal epithelial sodium channel: Genetic heterogeneity and implications for the treatment of high blood pressure. Curr Pharm Des12 (2006): 2221-2234.

2. Yamashita Y, Koga M, Takeda Y, et al. Two sporadic cases of Liddle's syndrome caused by De novo ENaC mutations. Am J Kidney Dis 37 (2001): 499.

3. Smith JH, Lindor NM, Rabinstein AA. Cerebrovascular consequences of pseudohyperaldosteronism. J Clin Hypertens (Greenwich) 14 (2012): 547-552.

4. Scheinman SJ, Guay-Woodford LM, Thakker RV, et al. Genetic disorders of renal electrolyte transport. N Engl J Med 340 (1999): 1177-1187.

5. Garovic VD, Hilliard AA, Turner ST, et al. Mono-genic forms of low rennin hypertension. Nat Clin Pract Nephrol 2 (2006): 624-630.

6. Canessa CM, Schild L, Buell G, et al. Amiloride-sensitive epithelial Na+ channel is made of three homologous subunits. Nature 367 (1994): 463.

7. Frindt G, Sackin H, Palmer LG. Whole-cell currents in rat cortical collecting tubule: low-Na diet increases amiloride-sensitive conductance. Am J Physiol 258 (1990): F562.

8. Bogdanović R, Kuburović V, Stajić N, et al. Liddle syndrome in a Serbian family and literature review of underlying mutations. Eur J Pediatr 171 (2012): 471-478.

Citation: Haia Nasser, Susan Nasser, Abo Zaid Said, Zohar Meiri, Ehsan N, Mariam Daher, Sami shhadi, Boshra Nasser, Wael Nasser. Liddle's Syndrome Case Report-Unusual Presentation with Hypertension in Children. Archives of Clinical and Medical Case Reports 2 (2018): 241-244.

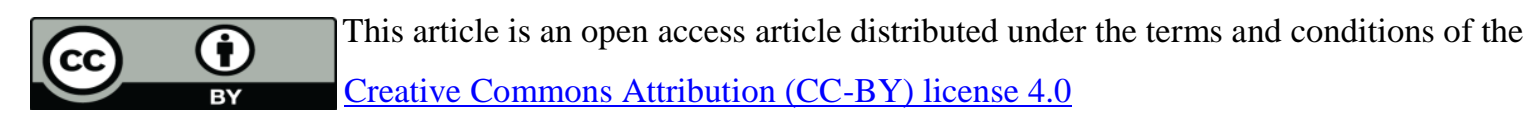

